\title{
El escritor que se pintó a sí mismo: Los figurines de Álvaro Retana
}

\author{
Sara Toro Ballesteros \\ Universidad de Belgrado
}

Título: El escritor que se pintó a sí mismo: Los figurines de Álvaro Retana.

Resumen: El propósito de este artículo es analizar las fructíferas relaciones entre literatura y moda en la obra pictórica y literaria del polifacético y no menos carismático Álvaro Retana (1890-1970). Para ello, nos centraremos en su biografía, así como en el estudio y comparativa de sus figurines para espectáculos de varietés con su novela Las locas de postín. Ambos, en apariencia frívolos, ofrecen un enfoque inusitado y progresista de la mujer y de la homosexualidad en la Espańa previa a la Guerra Civil.

Palabras clave: Álvaro Retana, Arte frívolo, Figurines de moda, Homosexualidad, Mujeres.

Fecha de recepción: 4/8/2015.

Fecha de aceptación: 19/8/2015.
Title: The Writer who Painted Himself: Álvaro Retana’s Figurines.

Abstract: The aim of this paper is to analyze the fruitful relations between literature and fashion among the literary and pictorial work of multifaceted and charismatic Álvaro Retana (1890-1970). In order to do so, his biography will be depicted, as well as a comparative study on his fashion sketches for variety performances in the novel Las Locas de Postin. Both, allegedly frivolous, show an unexpected liberal approach to the representation of women and homosexuality in Pre-Spanish Civil War.

Key words: Álvaro Retana, Frivolous Art, Fashion Sketches, Homosexuality, Women.

Date of Receipt: 4/8/2015.

Date of Approval: 19/8/2015. 
"Eso es el modernismo: un gran movimiento de entusiasmo y libertad hacia la belleza”

Juan Ramón Jiménez, La voz, 18 de marzo de 1935.

\section{ViVIR LA VIDA FRÍVOLA}

Álvaro Retana, Alvarito, César Maroto, Carlos Fortuny, Claudina Regnier son solo algunas de las máscaras del polifacético Álvaro Retana y Rodríguez de Arellano, autor objeto de este artículo y que, si por algo se caracterizó, fue por usar su propia vida como un lienzo con mágicas virtudes novelables. Tanto es así que, al evocar el episodio de su nacimiento en la autobiografía que acompaña a su ensayo Historia del arte frívolo (1964), Retana narra más que informa de lo que sigue:

Había nacido en alta mar, durante un viaje de mis padres a Filipinas, frente a Colombo, capital de Ceylán [sic], esa isla maravillosa donde dicen que estuvo el paraíso de Adán y Eva, prendida de Asia como un corazón rojo y verde, colores que parece ser marcaron mi destino.

Al desembarcar fui bautizado por el obispo en Batangas, lindo pueblecito de indios fieros y sensuales, cercano a Manila, donde residían mis abuelos, indicando como fecha de mi nacimiento el 26 de agosto de 1890, bajo la influencia que nunca pude explicarme de Virgo, signo del Zodíaco con el cual me declaro incompatible.

Por la gracia de Dios vine a este mundo inteligente, optimista, trabajador, ardiente y desdeńoso para los prejuicios sociales. Desde muy niño dividí a la humanidad en dos grandes grupos: en uno yo solo y en el otro la demás gente, gentecilla y gentuza.

[...]

Inicié estudios universitarios que no pude acabar. Escribir, pintar, idear decorados, componer música ligera, era cuanto me apetecía. Mi padre me dejó por imposible, rebelde, caprichoso, deslenguado.

[...]

Mi formación intelectual se la debo a autores extranjeros: Emilio Zola, Catulle Mendés, Arsenio Houssaye, Maupassant, Oscar Wilde, 
Colette, Huysmans, Rachilde, Barbey d'Aurevilly, Villiers de l'Isle Adam, Jean Lorrain... Si ardiese mi biblioteca salvaría Las mil y una noches que es mi obra favorita ${ }^{1}$.

Esta etopeya rojiverde, que da buena cuenta del carácter multidisciplinar del artista, viene motivada por la contemplación desde la senectud de un autorretrato [Fig. 1] de sus inicios literarios en El Heraldo de Madrid, cuando contaba con 21 años de edad -o 13- si atendemos a las biografías falseadas incluidas en la contraportada de algunas de sus novelas, que retrasaban a 1898 el año natalicio. Los cuentos galantes y las crónicas subidas de tono que publicaba bajo el heterónimo de la joven francesa Claudina Regnier en revistas y periódicos satíricos como El Gran Bufón, Madrid cómico o La Hoja de Parra y las novelitas que nutrían las, por entonces muy populares, colecciones de narrativa breve, no solo hicieron enrojecer a las mentes más morigeradas, sino que pusieron verdes de envidia a los "Unamunos", que así llamaba Retana a los escritores más preclaros del 98.

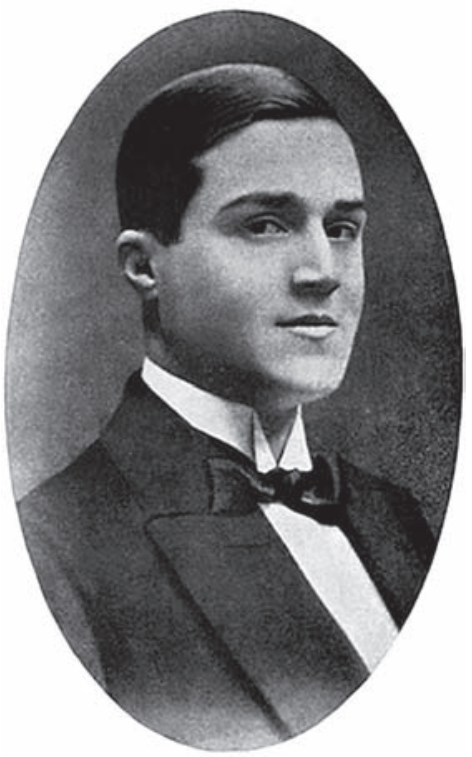

Fig. 1. Autorretrato de Retana aparecido en Historia del arte frívolo, 1964.

1 Álvaro Retana, "Autobiografía", en Historia del arte frivolo, Madrid, Editorial Tesoro, 1964, pp. 21-22 (p. 21). 
Uno de los motivos del resentimiento de los "Unamunos" se debe en parte a que, mientras que Felipe Trigo -padre literario de Retana como también de otros agitadores de la novela erótica como Eduardo Zamacois, Joaquín Belda o José María Carretero, más conocido por su alter ego de firma El Caballero Audaz- ingresaba 60.000 pesetas al año gracias a los royalties de sus novelas, los ingresos anuales de Pío Baroja apenas superaban las 3.000 pesetas anuales ${ }^{2}$.

$\mathrm{Si}$ Trigo fue uno de los primeros novelistas en vivir rodeado de lujo gracias a sus derechos de autor, Retana no le iría a la zaga al médico y novelista de Villanueva de la Serena. En la entrevista que sirve de pórtico a su polémica novela El tonto (1925) le cuenta al periodista Mariano Tomás (1890-1957) que en 1922 había comprado en Torrejón de Ardoz una finca valorada en 18.000 duros que había transformado "en un verdadero y palpable palacio episcopal"”. No faltaba detalle en la suntuosa residencia: un patio andaluz con celosías, estanque, surtidores, rejas de estilo sevillano e incluso un azulejo con la imagen de la Virgen de la Macarena enseñoreando la fachada principal.

2 Véase Maite Zubiaurre, "El novelista más guapo del mundo: Álvaro Retana y la sicalipsis", "Introducción" a Álvaro Retana, Las locas de postín; Los ambiguos; Lolita buscadora de emociones; El tonto, ed. Maite Zubiaurre, Audrey Harris y Wendy Kurtz, USA, Stockcero, 2013, p. XVI. Recogen esta misma idea los trabajos de Carmen Bassolas, La ideología de los escritores. Literatura y política en La Gaceta Literaria (1927-1932), Barcelona, Fontamara, 1975, p. 282, y José María López Ruiz, Del Madrid del cuplé, Madrid, El Avapiés, 1988, p. 41.

3 Mariano Tomás, "A manera de prólogo", Álvaro Retana, El tonto, p. 118. Gracias al trabajo de Pilar Pérez Sanz y Carmen Bru Ripoll, "Álvaro Retana «El sumo pontífice de las variedades"”, La sexología en la España de los 30, Revista de sexología, IV, 20-21 (1989), p. 18, podemos conocer detallado inventario del autor, en el que consignaba el precio, procedencia y ubicación de los enseres y objetos que adornaban cada sala, podemos reconstruir cómo fue su finca, cuyas estancias había renombrado con suntuosos nombres. Así pues, el salón César Borgia contenía, además del trono de su majestad Álvaro Retana (Rey de su casa), la calavera de Tina de Jarque que, en palabras del autor: «La adquirí en las Grandiosas Américas del Rastro, en el cuarto o quinto bazar, conforme se entra a mano izquierda. Me costó veinte pesetas. La cubrí con una mantilla negra y le puse un abanico y un ramito de rosas. La armadura y pie, realización de Emilio Hart. La instalación eléctrica efectuada por Eloy Gómez López de Núñez de Balboa 7». 


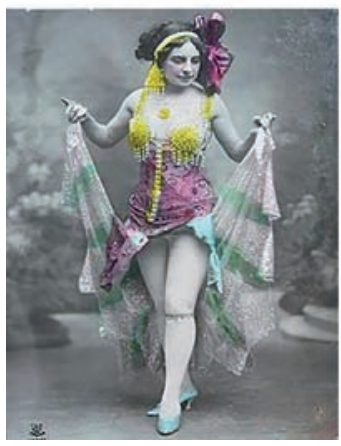

Fig. 2. La Chelito.

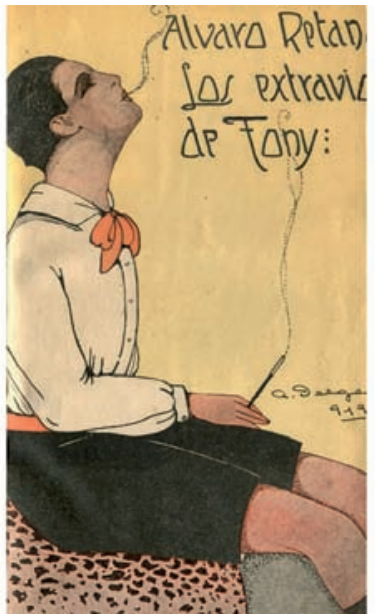

Fig. 3. Portada de Los extravios de Tony.

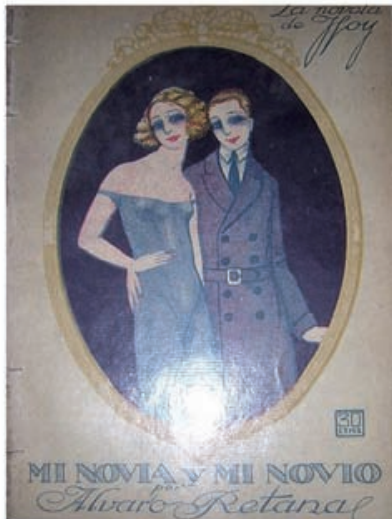

Fig. 4. Mi novia y mi novio de Álvaro Retana

A mediados de los felices veinte, Álvaro y sus máscaras habían publicado casi ochenta obras entre novelas, cuentos y libretos para espectáculos de varietés. Una monografía sobre la vida y la obra de La Chelito ${ }^{4}$ (1930) [Fig. 2], Los extravios de Tony (1919) [Fig. 3] -novela de iniciación con tintes autobiográficos que se comentará más adelante-, La carne de tablado (1918), Ninfas y sátiros (escenas pintorescas de Madrid de noche) (1918), El principe que quiso ser princesa (1920), El vicio de color de rosa (1920), La mala fama (1922), Mi novia y mi novio (1923) [Fig. 4] o la novela de costumbres aristocráticas Las locas de postin $(1919)^{5}$ son algunos de sus

4 Cuenta Retana en Historia del arte frivolo que Consuelo Portella Audet, conocida como la Bella Chelito, había nacido en las postrimerías del XIX en Santa Clara (Cuba) y que debutó con tan solo 14 años en el consagrado París-Salón de calle Montera. Consuelo comenzó cantando y bailando en las reuniones que organizaban en casa sus progenitores y a las que asistían, entre otros, Ramón Gómez de la Serna y Azorín, quienes aconsejaron a los padres de la joven promesa que se dedicase al teatro. Véase Álvaro Retana, Historia del arte frivolo, p. 176.

5 Existe una primera edición de esta novela publicada en Madrid en la colección Afrodita de la Biblioteca Hispania en torno a 1919, según fecha que da entre interrogantes el catálogo de la Biblioteca Nacional de España y que recogen en sus estudios: Luis Antonio de Villena, "Introducción" a Álvaro Retana, Las locas de postín, Madrid, Odisea, 2004, pp. 5-26, (p. 15), y Javier Barreiro, "Álvaro Retana en la eroto- 
exitosos trabajos anteriores a la Guerra Civil. Los títulos hablan por sí solos de la laxitud en materia de costumbres sexuales de la época en la que vieron la luz, una época marcada por la proliferación de locales en los que guayabos, tobilleras, chulos y aristócratas perversos acudían a ver cantar y bailar a las -cada vez más ligeras de ropa- estrellas del momento. Tanto es así que el propio monarca Alfonso XIII aportó no sólo el capital necesario para rodar las primeras películas pornográficas en España sino que también sugirió a la productora tramas y escenas que le apetecía visionar ${ }^{6}$.

A pesar de la aparente erotomanía que dominaba todas las esferas del poder y de que Retana parecía dominar tanto los salones de la nobleza como los teatros y los cafés de la bohemia, al estallar la Guerra se le incautó su finca y se le depuró en el Tribunal de Cuentas, puesto que había ganado por oposición instado por su padre Wenceslao Emilio Retana y Gamboa. Según relata Álvaro Retana en el prólogo a su novela Los ambiguos, la publicación de El capricho de la marquesa, otra de sus novelas breves subidas de tono, encendió la ira de su padre que, por aquel entonces, era Inspector General de Policía en Barcelona; cargo que aprovechó para denunciar la obra por inmoral y hacerla retirar de librerías y quioscos. Más grave fue la sanción de cinco meses de cárcel que la censura de Primo de Rivera le llegó a imponer por El tonto ${ }^{7}$.

grafía del primer tercio de siglo. Un acercamiento a los textos del cuplé sicalíptico” en «https://javierbarreiro.wordpress.com/2014/03/05/Alvaro-retana-en-la-erotografia-del-primer-tercio-de-siglo-un-acercamiento-a-los-textos-del-cuple-sicaliptico/». Originalmente el artículo se publicó en el Anejo XI de Analecta malacitana, El cortejo de Afrodita. Ensayos sobre literatura hispánica y erotismo, ed. Antonio Cruz Casado, Málaga, Universidad de Málaga, 1997, pp. 267-284. Jacqueline Heuer, "Álvaro Retana recuperado", en Actas XIII Congreso de la Asociación Internacional de Hispanistas, Madrid, Castalia, 2000, II, pp. 643-654, sin embargo, posterga a 1920 la fecha de la publicación (p. 646).

6 Así lo señala Lily Litvak, Antología de la novela corta erótica española de entreguerras (1918-1936), Madrid, Taurus, 1993, pp. 20-21, en la que cuenta que el monarca: "castizo, noctámbulo, deportista, mujeriego, populista, gustaba de la pornografía".

7 En el número monográfico de La revista de sexología dedicado a Retana, Pilar Pérez Sanz y Carmen Bru Ripoll, "Álvaro Retana "El sumo pontífice de las variedades»", La sexología en la España de los 30, Revista de sexología, IV, 20-21 (1989), pp. 14-15 y 21-22, señalan que, de los cinco meses de condena en la Cárcel Modelo, Retana solo llegó a cumplir una quincena. Sin embargo, el 14 de agosto de 1928 ingresó de nuevo en la cárcel tras la publicación de su versión de Los extravios de Tony, Un nieto 
El argumento de la novela, como el de muchas de su producción sicalíptica, es una sucesión de excusas para hilar un episodio sensual tras otro. Aurelia, una gentil cocotte rodeada de vejestorios a la que se refiere como una "Sherezada modern style", ameniza las tertulias leyendo a sus invitados pasajes de literatura galante de un autor -sobreentendemos que es el propio Retana- al que es adicta. Cuando se le acaban las novedades editoriales, entretiene a la senil audiencia con traducciones de autores clásicos consagradamente libertinos, así como de otros contemporáneos europeos que había conocido en sus continuos viajes. Sin embargo, llega un momento en el que Aurelia se queda sin historias y decide recurrir a su propio currículum sentimental. Además de por lecturas eróticas, su iniciadora en el sexo es -como no podía ser de otra forma-su profesora de francés. En la casa de la profesora doña Julia conoce a Polín, un "cadete de infantería muy pintado, de pelo negrísimo y crespo, carnación nacarina y ojos de color de las uvas tintas, que fumaba en una boquilla de media vara, sentado a la oriental sobre un almohadón como un bibelot de tocador" . Aurelia descubre que en realidad Polín no es ningún cadete de infantería, sino el mantenido de una vieja con cara de bulldog que decide renegar de su destino de muńequito de lujo y volver a su antiguo oficio de aprendiz de carpintero. La novela termina con el vano intento de Aurelia de perder la virginidad con el efebo, que parece inmune a sus caricias.

Maite Zubiaurre, Audrey Harry y Wendy Kurtz señalan en el prólogo a su cuádruple edición de Las "locas" de postín, Los ambiguos, Lolita buscadora de emociones y El tonto que el tonteo -de aquí el nombre de la novela- no consumado entre la lolita y el efebo puede leerse "como un ataque frontal a la masculinidad y, por ende, a la nación: no debemos olvidar que en esa España de capa caída, perdedora de sus últimas colonias, la identidad nacional se percibía como íntimamente vinculada a la identidad heterosexual" ${ }^{10}$. Por tanto, la labilidad de fronteras entre sexos de

de Don Juan, llegando esta vez a cumplir uno de los tres meses de condena impuesta. Más tedioso sería su ingreso en prisión en 1939, que con algunas intermitencias de libertad se prolongaría hasta el verano del 48.

8 Álvaro Retana, El tonto, p. 124.

9 Ibidem, p. 133.

10 Maite Zubiaurre, "El novelista más guapo del mundo: Álvaro Retana y la sicalipsis", en su "Introducción" a Álvaro Retana, Las locas de postín, p. XXI. 
la propuesta estética de Retana hacía peligrar los principios de soberanía masculina defendidos desde el poder, entre otros, por Gregorio Marañón.

Otro de los atrevimientos de Retana que también debió importunar al régimen de Primo de Rivera tiene que ver con las declaraciones de la citada entrevista que prologa El tonto. Retana confiesa a Mariano Tomás tener en su finca un altar laico tapizado de terciopelo rojo y adornado con candelabros de plata y floreros de cristal. Presidiendo el altar se encontraba él mismo en calidad de dios mayor, y a los lados, en calidad de santos de su devoción, la humorista y bailarina Luisita Esteso ${ }^{11}$, Mercedes Fifí ${ }^{12}$, Matilde del Castillo, Antonia de Cachavera ${ }^{13}$, tres jóvenes muchachos y

11 Recoge Álvaro Retana en su Historia del arte frivolo, p. 311, que la nińa prodigio, hija de Luis Esteso y Polonia Herrero Amat, La Cibeles contaba con las piernas más bonitas del mundo de las variedades. El estilo de Luisita estaba basado en el humorismo estético sin necesidad de gesticulación y actitudes grotescas. A mediados de los sesenta poseía un importante patrimonio inmobiliario atesorado con el fruto de su trabajo.

12 De las numerosas mujeres que pasaron por la vida de Retana, sólo calificó de novias a Luisa de Lerma, Margarita Ferreras, Nena Rubens, Mercedes Fifí y a Floriana y Lina Valery. Véanse Pilar Pérez Sanz y Carmen Bru Ripoll, op. cit., p. 33. Retana la retrata en la p. 166 de su Historia del arte frivolo como una apasionada intérprete de segunda división que "gustaba de la coexistencia de poetas y novelistas y, estilizada por su relación con ellos, acabó experimentando vocación literaria. Sus cartas, como las de "madame" de Staël, hubieran sido dignas de publicación. Inspiró a Emilio Carrere pulidos versos y a Álvaro Retana su relato «El más bello amor de Mercedes», aparecido en «La novela de hoy» hacia 1925. [...] Presidía en el Coliseo dos Recreios, de Lisboa, donde actuaba, una peña de asiduos integrada por un ruso nada arisco, un chino que no fumaba opio, un argentino que no cantaba tangos y un norteamericano que no mascaba chicle".

13 Retana le dedica tres fotografías y las pp. 332 y 333 de su Historia del arte frivolo. Cuenta que fue la estrella del Paralelo de Barcelona durante largo tiempo y que en la temporada que realizó en Bilbao en el año 1935 la autoridad tenía que enviar docenas de antidisturbios para contener al auditorio, encendido por una súbita "rebelión de la carne". Y es que: "Desde su debut combatieron en ella un ángel y un demonio. Este era quien actuaba en los "music hall", soliviantando los espíritus, y el otro el que la acompañaba, terminado el espectáculo, a la severidad de su hogar inaccesible" (Álvaro Retana, Historia, p. 332). Afirma Retana que por su cultura, inteligencia y peregrino ingenio Antonia de Cachavera hubiera rivalizado con Aspasia o con Madame Sévigné, "pero nacida en el XX, hubo de avenirse a competir con las primeras figuras del género chico, vodevil, revista y variedades" (Álvaro Retana, ibidem, p. 332). 
un par de bellas admiradoras. A una de ellas, la barcelonesa María Antonia, va dedicada precisamente El tonto.

Tras cumplir su mes de condena, Álvaro Retana, en una artera estratagema de autobombo, vuelve transmutado en su habitual entrevistador Carlos Fortuny con Critica frivola. La ola verde, donde trata de vengarse de sus compañeros de profesión, que lo habían abandonado sin reparos en las garras del dictador. La tesis que defiende en La ola verde es bastante clara: Eduardo Zamacois, Hoyos y Vinent, Alberto Insúa, Luis Antón del Olmet, Felipe Sassone, Artemio Precioso, Joaquín Belda y el resto de compañeros de generación escribían literatura erótica, y si no la escribían en puridad, sí que trataban de describir la pasión amorosa en sus obras y no por ello acabaron en la cárcel ${ }^{14}$.

Tampoco le apoyó el Marqués de Portazgo del que, por otra parte, conocía sórdidas historias, ni tampoco sus amigos de la alta sociedad cuando fue condenado a muerte en juicio sumarísimo el 17 de mayo de 1939 por la causa que se describe en el acta procesal que aquí se extracta:

Probado y así se declara por el Consejo que el procesado, antiguo escritor pornográfico, durante el dominio rojo se aprovechó de su amistad con los dirigentes marxistas para apoderarse de objetos sagrados con los que decoró su estudio mezclándolos con propósito de escarnio con pinturas y retratos inmorales; que en una carta dirigida al Jefe del S.I.M. pide a este textualmente "una custodia grande para incrustarle por un lado un reloj y por el otro el retrato de la Chelito; un cáliz para poner tres cosas con los colores de la bandera republicana y una imagen del Niño Jesús para vestirlo de miliciano con un fusil al hombro, etc." ${ }^{15}$.

14 Véase Carlos Fortuny [Álvaro Retana], Crítica frivola. La ola verde, Barcelona, Jasón, 1931, pp. 302-303. Antonio de Hoyos y Vinent acabó en prisión al terminar la Guerra Civil, pero no por sus novelas, sino por haber militado en la FAI (Federación Anarquista Ibérica) y por sus artículos en El Sindicalista. Artemio Precioso, por su parte, recuerda en Españoles en el destierro: La vida en Francia de Santiago Alba, Blasco Ibánez, Sánchez Guerra, Unamuno, E. Ortega y Gasset, Carlos Esplá, López Ochoa y Manteca: con diálogos, anécdotas, cartas y semblanzas de estos ilustres perseguidos, Madrid, Talleres Poligráficos, 1930, p. 98, que se exilió en 1929 para no cumplir la condena por escándalo público por la que le condenaron "a la pena de seis meses y no sé cuántos días de cárcel, a mil pesetas de multa y a once años de inhabilitación para cargos públicos, y no sé si a algo más".

15 Pilar Pérez Sanz y Carmen Bru Ripoll, op. cit., pp. 20-21. 


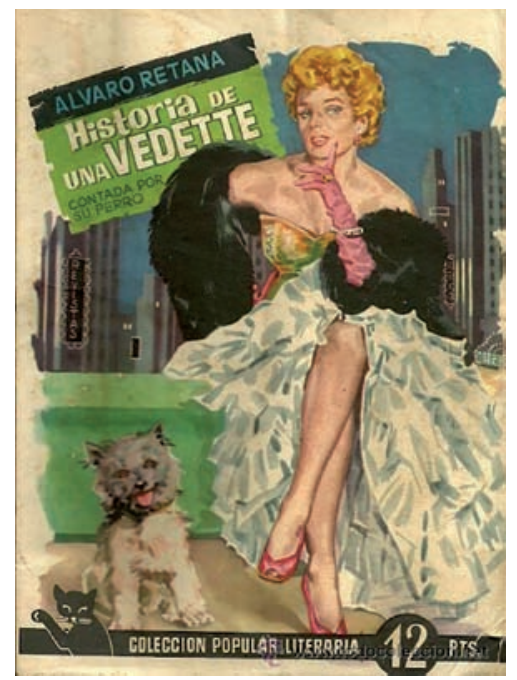

Fig. 5. Historia de una vedette contada por su perro.

Ante la acusación del fiscal de que usaba un copón bendito para beber semen de sus amantes, Retana hace gala de un aplomo y un sentido del humor que jamás le abandonaría y contesta: "Señor, prefiero siempre tomarlo directamente" 16 . Tras aplazar varias veces su ejecución, se le conmutó por treinta años de cárcel, de los que cumplió prácticamente una década; puesto en libertad y recuperado su empleo en el tribunal de cuentas en el año 1957, Álvaro continuó con sus múltiples actividades, que no había abandonado en prisión, e incluso vivió un pequeño renacer con el taquillazo de El último cuplé. También volvió a publicar ensayos sobre el género que tan bien dominaba como: Estrellas del cuplé o Estrellas del arte frivolo, además del ensayo Historia del arte frivolo y una novela de las que tanto gustaban en su juventud, como Historia de una vedette contada por su perro (1954) [Fig. 5], si bien en 1970, habiendo cambiado su más que saqueada mansión, por una humilde buhardilla en el madrileńo barrio de San Bernardo, murió - cuentan que asesinado por un chulo- ${ }^{17}$, pero sobre

16 Javier Barreiro, Cruces de bohemia: Vidal y Planas, Noel, Retana, Gálvez, Dicenta y Barrantes, Zaragoza, Una Luna, 2001, p. 94.

17 Luis Antonio de Villena, El ángel de la frivolidad y su máscara oscura (vida, literatura y tiempo de Álvaro Retana), Valencia, Pre-textos, 1999, pp. 99-100, se hace eco de los 
todo asesinado por la Espańa del olvido. Como no podía ser de otra manera, en su testamento dio muestras tanto de su humor como de su ironía:

Deseo que no se guarde luto por mi muerte. [...] No hay por qué llorar a un extinto, puesto que quien muere descansa y, siendo como yo, deja descansar a los demás. A mis pies se colocará una cinta con los colores de la bandera española y un cartelito que diga: MIERDA PARA LOS QUE QUEDAN. [...] [Hago] constar que muero sin perdonar a cuantos elementos del régimen de Francisco Franco Bahamonde se han complacido en perseguirme, difamarme y desdeñarme, con ese implacable rencor que distingue a tantos titulados católicos, apostólicos romanos, compostelanos y hasta del puente de Vallecas, partidarios de restaurar la siniestra Espańa de Felipe II.

Si es verdad que existe el infierno, como allí nos encontraremos todos, procuraré hacerles imposible la vida eterna, con la colaboración especial de Satanás que, seguramente, será conmigo menos infame y rencoroso que ellos, a quienes me gustará ver cómo les queman los cuernos.

No terminaré este testamento, sin proclamar que fallezco sin acusarme de otros pecados que los exclusivamente de alcoba; perpetrados siempre sin perjuicio de tercero y de acuerdo con la parte beligerante, que invariablemente solicitaba una repetición ${ }^{18}$.

Ese es el legado que le dejó a Alfonso, su único hijo, fruto de su relación con su primera "esposa experimental"19, la bailarina Luisa Tejeira de Lerma ${ }^{20}$.

rumores en torno a su muerte. También habla de asesinato Alberto Álvarez-Insúa, Bibliografía e historia de las colecciones literarias en España (1907-1957), Madrid, Libris, 1996.

18 Pilar Pérez Sanz y Carmen Bru Ripoll, op. cit., pp. 26 y 28. En el prólogo a su novela El encanto de la cama redonda, publicada el 1 de diciembre de 1922, Retana pedía ser enterrado con una túnica con los colores patrios y un sombrero cordobés en un ataúd forrado con retratos de cupletistas. En lugar de los habituales crespones negros, Álvaro pedía que la sala del velatorio estuviese adornada con mantones de Manila, pues exigía que su entierro fuese una manifestación de regocijo; incluso proponía un concurso con un premio de 5.000 pesetas para la persona que pronunciase el discurso más divertido sobre él (pp. 7-8). Las mayúsculas de la cita del testamento se presentan así en el original.

19 Ibidem, p. 33. Además de Luisa de Lerma, fueron "esposas experimentales" de quien nunca pasó por la vicaría Lina Valery y Nena Rubens. Aurora Purificación Mañanós Jauffret, más conocida como La Goya, fue la madrina de su hijo Alfonso.

20 Cuenta Retana que la madrileña Luisa de Lerma actuó en el Metropolitan de Nueva 


\section{Dibujar el GÉNero Frívolo}

Desde finales de los 80 del pasado siglo XX hasta la actualidad, muchos críticos han tratado de proyectar un haz de luz sobre el autor al que la escritora francesa Myssia Darrys denominó como "el novelista más guapo del mundo" [Fig. 6]. El "epíteto épico" de la ficticia Darrys era uno de sus remoquetes preferidos junto con el de "Petronio español de nuestro tiempo" ${ }^{21}$ que le aplicó no una de sus múltiples máscaras, sino el crítico literario Julio Cejador Frauca, que en su Historia de la Lengua y la Literatura Castellanas le apodó de esta manera por ser "el escritor más travieso en asuntos y el más elegante, ameno y delicado en la forma" 22 .

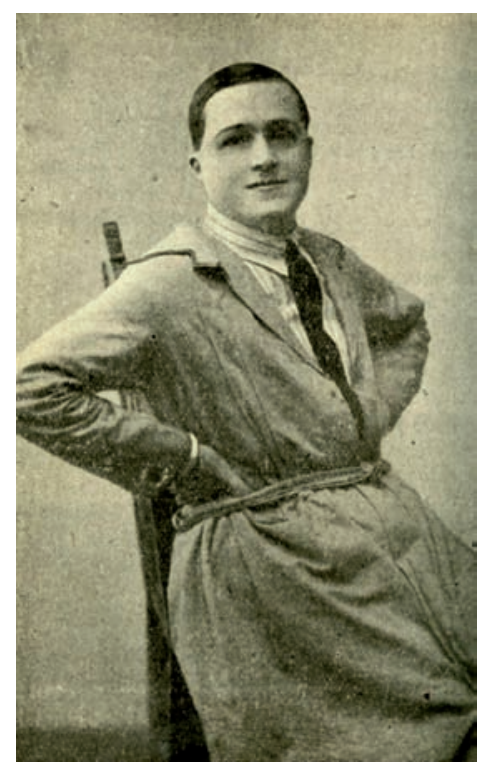

Fig. 6. El novelista más guapo del mundo.

York y que el éxito la acompañó por México, Argentina e incluso Hollywood, pues Blasco Ibáńez la escogió para bailar un tango junto a Rodolfo Valentino en la versión cinematográfica de Los cuatro jinetes del Apocalipsis. Asimismo, incluyó en los repertorios de sus actuaciones la música de Albéniz, Falla, Granados, Giménez y Rimski-Kórsakov, contribuyendo a la distribución de dichos compositores entre el gran público. 21 Julio Cejador Frauca, Historia de la lengua y la literatura castellanas. XIII, Madrid, Tipografía de la Revista de Archivos, Bibliotecas y Museos, 1920, p. 181.

\section{Ibidem.}


La materia espiritualista de Retana, como se puede ir vislumbrando por los detalles expuestos hasta ahora, era la de crear y recrear de continuo un trampantojo de sí mismo, ya fuese en sus autorretratos fotográficos, ya en los textuales o plásticos. Justamente a los 13 ańos, pero no a los 13 que proclamaba en 1911, sino a los verdaderos, comenzó su actividad artística en el campo de la ilustración gráfica en el periódico escolar Iris, donde colaboró con el famoso figurinista y dibujante José Zamora.

Petito Zamora compartía con Retana la afición por el juego del equívoco heteroflexible, así como la costumbre de quitarse una década de encima. Asimismo, al igual que hiciera su amigo, se dedicó a ilustrar algunas revistas del Madrid de su adolescencia, como Nuevo Mundo y La Esfera, hasta que entró a trabajar en París como figurinista en el taller de uno de los creadores de alta costura más célebre de su tiempo: Paul Poiret. Allí trabajó y trabó amistad con Erté, uno de los principales agitadores del art decó.

Ante el inminente desencadenamiento de la I Guerra Mundial, Zamora volvió a Espańa y a su antiguo empleo en La Esfera ${ }^{23}$, que alternó con la aguja y el pincel con igual fortuna tanto en la elaboración de decorados para los tablaos de varietés como en el diseño de trajes para el ballet de Serguéi Diáguilev. También realizó las portadas para las célebres canciones "del maestro Padilla" y para completar esta sinergia artística se lanzó a escribir novelas, aunque con menos tino y fama que su amigo "El Petronio espańol", de quien, por otra parte, ilustraría El príncipe que quiso ser princesa, El más bello amor del rey y El capricho de la marquesa.

Los títulos anteriormente citados dan cuenta por sí solos del atractivo por el boato nobiliario en la literatura galante, que gustaba de ambientar sus tramas en los garitos nocturnos en los que alternaban por igual toreros en ciernes, cupletistas de moda y aristócratas. Así, no es de extrañar que los compañeros habituales de correrías de Pepito Zamora fueran el marqués Antonio de Hoyos y Vinent y la exótica bailarina Tórtola Valencia. Los dos

23 Como bien señala Luis Antonio de Villena, revistas como Blanco y negro, La Esfera, las editoriales Hispania, Colombia y las colecciones de narrativa breve "La Novela de Hoy", "La Novela Corta", entre otras, "crearon o reflejaron una voracidad lectora de clases no intelectuales que estaban ávidas de nuevas sensaciones o de vicios secretos que -entre otras cosas, y como siempre- debían sacarles de la tépida rutina y colmar [...] su sed de aventuras". Véase Luis Antonio de Villena, "Álvaro Retana, en el abanico de la 'novela galante-decadente", Turia. Revista cultural, 21-22 (1992), pp. 19-28 (p. 21). 
primeros aparecerían retratados con frecuencia en las novelas de Retana, unas veces con sus nombres y apellidos y otras bajo nombres en clave, como sucede en Ninfas y sátiros, donde Zamora se convierte en el modisto y figurinista Juanito Basora y su cómplice de farras, Hoyos y Vinent, pasa a ser el marqués de Miláns Antonio de las Verdes Asturias y Bernáldez de Parrús.

El esfuerzo de Zamora por engalanar la vida -recuérdese que los oropeles de plumas, tul y lentejuelas que embellecían a las cupletistas ocultaban la realidad de su humilde procedencia- se vio truncado por su exilio a Francia durante la Guerra Civil. A su vuelta Pepito se instaló en Sitges junto a su novio José, dedicándose a la pintura de corte naïf. César González-Ruano, amigo de la pareja, a la que solía visitar a menudo, apunta en su diario íntimo:

Le quiero a Pepito y a José, el griego. Es sencillamente admirable esta elegancia suya de mostrarse siempre de buen humor aún en temporadas bien adversas. Jamás le he oído lamentarse de nada. Sigue jugando al joven frívolo a sus años. Hace falta para esto ser, de verdad, muy poco frívolo. Hace falta tener un alma muy seria para estar siempre riéndose. Hace falta ser muy hombre para empeñarse a través de una larga vida en no parecerlo ${ }^{24}$.

Efectivamente, hay que contar con un alma muy seria para mantenerse, aun en la adversidad, en la cara amable del humor y por supuesto para dedicarse al arte frívolo. En el prólogo a su Historia del arte frivolo (1964) Retana expone que, aunque normalmente se relaciona este tipo de arte con lo caprichoso, ligero y falto de importancia, es un tipo de arte respetado, celebrado y admirado por todas las naciones. Muchas actrices, -declara- que han representado repertorios clásicos son menos conocidas que la tonadillera Raquel Meller o el bailarín Antonio. Asimismo, el arte frívolo integra otras manifestaciones de la belleza a las que no se les suele otorgar la importancia que merecen, como la preparación del escaparate de unos grandes almacenes, unos pasos de flamenco, el peinado de un buen peluquero, Sara Montiel cantando una rumba o Tony Leblanc contando chistes. Además alega que es posible pasar del género frívolo

24 César González-Ruano, Diario intimo (1951-1964), Madrid, Comunidad de Madrid, Consejería de Educación y Visor libros, 2004, pp. 793-794. 
al elevado, pero no viceversa. Nadie puede negar que Zuloaga o Picasso fueron excelentes pintores; sin embargo, no tuvieron demasiada suerte como figurinistas de moda para el teatro. Por el contrario, Zamacois compuso poemas sinfónicos y Martínez Abades marinas sorprendentes, pero su celebridad, prestigio y beneficio económico provienen de sus cuplés, que Retana auguraba que serían famosos hasta el año 2000. El alegato en defensa del arte frívolo culmina con la afirmación de que uno nunca se duerme cuando suena el cuplé de El relicario, pero sí puede dormirse con una pieza musical clásica ${ }^{25}$.

No son pocos los beneficios de estar despierto, sobre todo cuando se trata de asistir a la renovación y el refinamiento del género frívolo a través de la obras pictóricas y literarias de Zamora y Retana, unas creacciones que buscaban retratar una belleza joven y andrógina envuelta en bastantes ocasiones en un velo de exotismo orientalista [Figs. 7 y 8]:

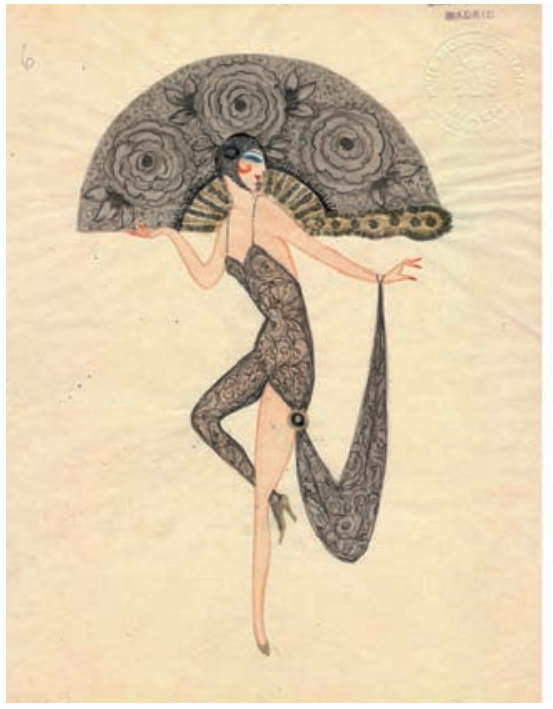

Fig. 7. Figurín de Álvaro Retana.

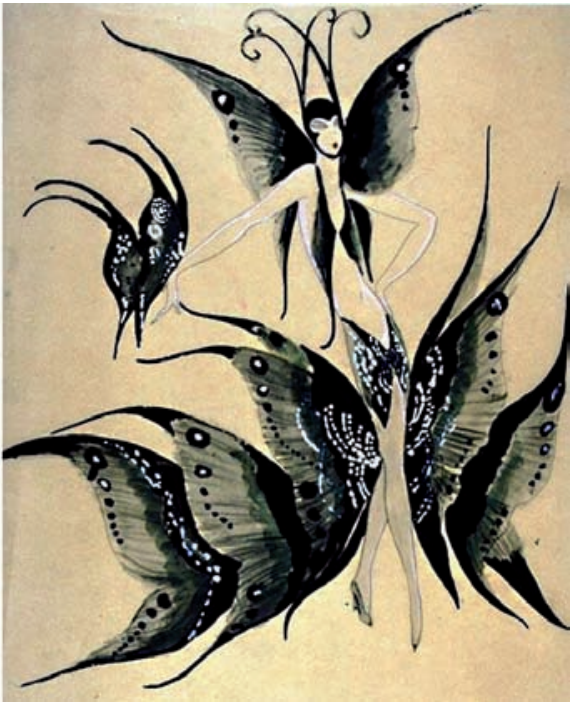

Fig. 8. Figurín de Pepito Zamora.

25 Álvaro Retana, “A manera de prólogo”, pp. 9-20 (pp. 10-17). 


\section{3. ¿Pero es QUe hay hombres aquí?: Maquillaje, Literatura y Deleite}

"No vivía para otra cosa que para el maquillaje, la literatura y el deleite"26, así describe Retana en Las locas de postín [Fig. 9] a Juanito Si-sí, un joven aristócrata con caprichosas inclinaciones literarias que recibía tal sobrenombre, "porque jamás había dicho que no a ninguna proposición contra natura" 27.

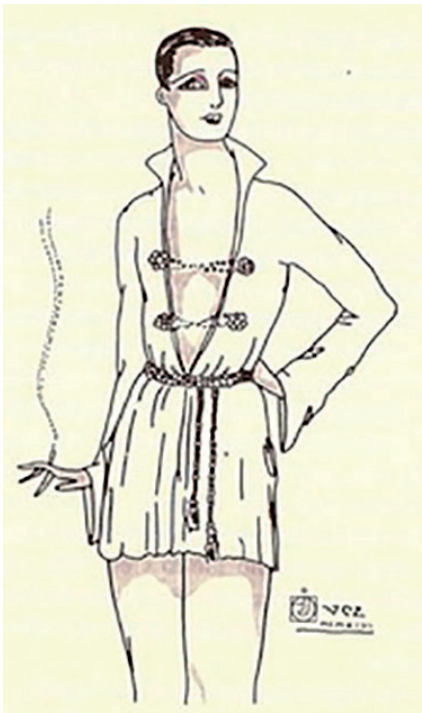

Fig. 9. Dibujo que acompanía a la edición de Las locas de postín prologada por Luis Antonio de Villena, p 89.

Las locas de postín es, al igual que Ninfas y sátiros, un roman à clef. Salvo el grotesco final en el que el protagonista trata de suicidarse metiendo la cabeza en una palangana, la trama es bastante sencilla: Rafaelito pierde el billete de mil pesetas que obtuvo como pago por sus favores sexuales al Marqués de Villamalo para descubrir finalmente que no ha sido una pérdida, sino un robo perpetrado por La Duquesa, su pretendido amigo, que, en confabulación con el hermano menor de Rafaelito, Guillermo -el único personaje abiertamente homófobo y heterosexual-, le robará otras dos mil pesetas.

26 Álvaro Retana, Las locas de postín, p. 42.

27 Ibidem. 
Aunque en algunos momentos la novela parezca abusar de la moralina, lo cierto es que, como afirma Luis Antonio de Villena, la novela es "atrevida e innovadora" 28 , pues nos brinda la oportunidad de reflexionar sobre la homosexualidad en una España intolerante y homofóbica que se parece muy poco a la actual en lo que a tolerancia y reconocimiento de derechos civiles del colectivo gay se refiere. Y es que Retana fue, ante todo, "el precursor de una nueva novela de costumbres y [...] uno de los escritores más significativos y característicos, de la nada desdeńable aunque coloquial prosa, de la novela española en la línea renovadora de los años veinte"29. No en vano, Las locas de postín se subtitulaba "novela de malas costumbres aristocráticas"; tanto es así que, gracias a las descripciones de Retana, podemos recrear el atuendo, el vocabulario y el modus vivendi de la high class madrileña de ese tiempo.

Merece la pena detenerse en "El apio maravilloso"30, capítulo IX de la novela en el que tiene lugar el episodio de la función del transformista Edmond de Bries. El graderío, encendido de pasión por el talento y la belleza de la tonadillera ataviada de goyesca, prorrumpe en insultos al grito de “¡Mariposa! ¡Goloso! ¡Apio!”31 al descubrir que la artista es en realidad un hombre travestido de mujer. Maite Zubiaurre compara este pasaje con otro similar del capítulo II, titulado “¡Ay, Jesús, cómo está el patio!”32. En él, Rafaelito y La Duquesa pasean por las principales calles de Madrid en un vistoso carruaje, cuando a su paso por Cibeles unos jóvenes que los contemplan vociferan: “A Apio! ¡Escarola! ¡Brecolera!”33. En este caso, ninguno de los dos amigos reacciona contra el pretendido ataque; es más,

28 Luis Antonio de Villena, "Las 'locas' de postín y a Sodoma en tren botijo: conciertos y disonancias", "Introducción" a Álvaro Retana, Las locas de postín, ed. Enrique Redel, Madrid, Odisea, 2004, p. 21.

29 Luis Antonio de Villena, "Álvaro Retana, en el abanico de la 'novela galante-decadente", p. 28.

30 Antonio Cruz Casado, "La moda femenina en las novelas eróticas en clave de Álvaro Retana (1890-1970)", en Moda y sociedad. Estudios sobre: educación, lenguaje e historia del vestido, eds. Emilio José García Wiedemann y María Isabel Montoya Ramírez, Granada, Centro de Formación Continua, 1998, pp. 223-234 (p. 231), señala que Álvaro Retana anunció en 1918 la intención de dedicar una novela a Pepito Zamora bajo el título de El apio maravilloso (Historia de un modisto-dibujante-bailarin).

31 Álvaro Retana, Las locas de postin, p. 41.

32 Maite Zubiaurre, op. cit., p. 23.

33 Álvaro Retana, Las locas de postín, p. 9. 
reafirman su autoestima a través de su apariencia - “'Somos demasiado jóvenes y hermosas para pasar inadvertidas!" ${ }^{4}$, sostiene La Duquesa- y de su clase social - "Debemos despreciar los alaridos de la chusma encanallada. Nuestra tranquilidad no puede estar a merced de unos plebeyos tumultuosos", apostilla Rafaelito"35 - Sin embargo, en el teatro, Edmond de Bries se defiende del público espetándoles: “¡Ay, qué cursis! ¡Ya no se dice apio! ¡Se dice vidrio!”36. Resulta irónico que sea Edmond de Bries, un chico de provincias llamado en realidad Ascencio Marsal, el que venga a la capital madrileńa a dar lecciones de modernidad a un auditorio en su mayoría aristocrático, y es que, como vienen señalando los estudios en torno a los creadores raros y olvidados de la Edad de Plata, la modernidad opera como una fuerza centrípeta y a la vez centrífuga en la que la marginalidad enriquece al centro y este a su vez se expande hacia los márgenes. De Bries se valió, como hiciera dos siglos antes Chatterton, de la falsificación para rodearse de lujo y cuestionar el saber establecido, pero en lugar de servirse de la literatura utilizó su propio cuerpo. No obstante, sus palabras requieren un poco de atención, pues considera demodé el término "apio", que años más tarde reviviría Lorca en su "Oda a Walt Whitman para nombrar a los homosexuales de Sevilla", y prefiere, en cambio, "vidrio", que en el diccionario no alude directamente a "el hombre afeminado", sino que se usa en sentido figurado para referirse a la persona de ánimo quebradizo que se enoja y desazona con facilidad. Una persona frágil, pero al fin y al cabo persona, no sólo ser humano de sexo masculino.

Notorio también que sea precisamente una mujer la que defienda al imitador de mujeres cuando tras uno de sus números recibe los clásicos abucheos: “¡Sape! ¡Bribón! ¡Sarasa! ¡Fuego!”37. La admiradora del transformista se sorprende de la antipatía de los insultadores y comenta a su grupo de amigas: "El chico, ¿no es el último número del programa? Pues al que no le guste que se marche. ¿Qué derecho tienen a ofenderle? Cada cual se gana la vida como puede, y con su trabajo no perjudica a nadie" 38 . Edmond de Bries, por su parte, se defiende de la petición de los jara-

34 Ibidem, p. 10.

35 Ibídem.

36 Ibidem, p. 40.

37 Álvaro Retana, Las locas de postín, p. 41.

38 Ibidem. 
neros de que imite a un hombre, respondiendo desafiante: "Pero, ¿hay alguno aquí?" 39 . Todo esto es posible gracias a que el teatro, a diferencia de la calle, ofrece un entorno seguro en el que responder a las ofensas e incluso al permitir "que una audiencia "mixta" (homosexual y heterosexual) se enfrente abiertamente con un tabú y conozca los entresijos de una sexualidad que vuelta estigma contribuye a la normalización de la homosexualidad" 40 .

En su Diccionario gay-lésbico Félix Rodríguez recoge multitud de testimonios en los que aparece el adjetivo "loca", que se utiliza despectivamente para referirse "al homosexual muy amanerado, con mucha pluma; y por extensión a cualquier cosa relacionada con él” ${ }^{41}$. Retana retrata con minuciosidad y en primicia todo lo "malo", todo lo que tiene que ver con el "tercer sexo", que así se denominaba a la homosexualidad en su época. Así, perfila toda una tipología de "locas" que van desde la loca por convicción a la loca vetusta, pasando por la romántica, la escandalosa, la profesional y la en entredicho. Como ejemplo de loca escandalosa cita a "Pepito Rocamora, el joven dibujante de elegancias femeninas y su inseparable camarada de correrías Aurelio de Regoyos, novelista aristocrático de fama universal" 42 ; y como ejemplo de loca por convicción, a Sarabia, "el modisto aristocrático, que ha convertido en seńoritos a tantos organilleros" ${ }^{43}$. Se adivina que Rocamora y Regoyos son las máscaras de Zamora y Hoyos y Vinent, que, como se ha apuntado anteriormente, aparecían de continuo en sus novelas, pero resulta necesario en este punto detenerse en "la loca por convicción”. En las palabras liminares del prólogo a Las locas de postín Retana invita a los lectores a abominar del tercer sexo, pero se debe hacer caso omiso a esta afirmación, puesto que al principio del preámbulo se confesaba "buscador insaciable de emociones morbosas" ${ }^{44}$. Además fomentó el empoderamiento del tipo de homosexual más vilipendiado de todos, pues la loca con su pluma, sus plumas y su convicción goza del

39 Ibidem.

40 Maite Zubiaurre, Culturas del erotismo en España (1898-1939), Madrid, Cátedra, 2014, pp. 375-376.

41 Félix Rodríguez, Diccionario gay-lésbico, Madrid, Gredos, 2008, p. 255.

42 Álvaro Retana, Las locas de postín, p. 34.

43 Ibidem.

44 Álvaro Retana, “A manera de prólogo”, en Las locas de postín, p. 1. 
privilegio de poder desclasarse. Mediante el uso de su habilidad para el artificio, el modisto es capaz de convertir en señoritos a organilleros, y toda loca sabe que lo más importante no es serlo sino parecerlo. Esto entronca directamente con la estética y la ideología del dandi.

El dandi se caracterizaba sobre todo por abjurar de lo natural, por cultivar la diferencia en el siglo de lo uniforme. El dandi y la loca son, como el art decó, fundamentalmente figurativos, es decir, sólo existen en tanto que exhibición artística, pues ambos son las exclusivas piezas de arte de sus figurines. Sin sus esmaltes, joyas y cromados que los vuelven únicos y diferentes pierden su esencia y sólo queda la funesta melodía del organillero. En resumidas cuentas, no puede haber un dandi sin ostentación, no puede haber un dandi de andar por casa. El propio Retana gustaba de ataviarse con quimonos y batines de seda aun en su hogar; de hecho, a mediados de los veinte planeaba ofrecer lo que él llamaba "conferencias escenificadas", en las que dice: "Me presentaré con esta misma indumentaria casera que me ves ahora [...]. Pintaré figurines a la vista del público, haré desfilar maniquíes vivientes para ilustrar mis conferencias sobre modas femeninas [...]. En fin, será algo muy divertido, propio para damas honorables y caballeros frívolos" ${ }^{35}$.

Por definición el dandi es un hombre invariablemente elegante y en permanente búsqueda de la belleza, y es que, como afirmaba Balzac en El tratado de la vida elegante, "el principio de la vida elegante se basa en un elevado concepto de orden y de armonía, destinado a conferir poesía a las cosas" ${ }^{46}$. Pero como su indagación no tiene por objeto atraer a la sociedad, sino diferenciarse de ella, el dandi se ve obligado a disimular el hastío y la pena bajo una capa de ironía, que es el corrector de tristezas de la retórica.

45 Álvaro Retana, Álvaro Retana: el Petronio del siglo XX: biografía del famoso escritor galante, único en su género, Retana novelista picaresco, Alvarito artista enciclopédico, compositor, dibujante, actor, "astro" de la cinematografía española, Barcelona, Biblioteca Films, 1926, pp. 15-16.

46 Honoré de Balzac, Charles Baudelaire, Jules Amédée Barbey d'Aurevilly, El dandismo, Barcelona, Anagrama, 1974. Apud AA. VV., Prodigiosos mirmidones. Antología y apología del dandismo, eds. Leticia García y Carlos Primo, Madrid, Capitán Swing, 2012, p. 75. 


\section{4. "DAMAS HONORABLES" y CUPLETISTAS ARISTOCRÁTICAS}

Yo desde mi más tierna infancia, he vivido para, con, de, en, sobre, tras la mujer. [...] Fui un niño precoz que a los trece años se dejó seducir por una opulenta jamona rubia y sentimental, madre de un compañero de colegio, y que a los diez y seis ya era amigo y confidente de La Goya, Adelita, Lulú, Preciosilla, Tórtola Valencia, Amalia Molina, Chelito, Olimpia d'Avigny y otras deidades no menos celebérrimas en el mundo del arte o la galantería.

Pero nunca la atracción que sobre mí han ejercido las mujeres ha sido exclusivamente carnal. [...] Me ha seducido su alma antes que su cuerpo, he observado sagaz y, utilizando mi arte como ganzúa, he abierto dulcemente sus "interiores" para curiosear en los más íntimos repliegues de su corazón. [...] En mis libros, ni por casualidad encontrará el lector una mujer irreprochablemente honrada. Me han parecido más sugestivas esas otras que llamamos "perdidas" que el que más y el que menos desearía encontrar. [....] Las mujeres honradas carecen en absoluto de historia, y el relato de sus altruismos resulta soporífero. En cambio las liviandades de las honestas deshonestas tienen siempre un interés que cautiva al novelista y contagia al lector. [...] Las protagonistas de mis libros más populares están todas en pecado mortal; pero huelen bien $^{47}$.

Otra de las innovaciones de la prosa retaniana es precisamente el tratamiento que reciben las mujeres, las cuales, además de por sus cualidades odoríferas, se diferencian de las que dibujan otros novelistas sicalípticos de su tiempo en que jamás se conciben desde la tradicional misoginia falocéntrica. Por ejemplo, Joaquín Belda en su obra Las mujeres de Belda (1921) confiesa lo siguiente:

Yo -lo digo con toda franqueza- tengo, en general, muy mal concepto de la mujer: creo que la apetecible hembra del género humano es una cosa sin terminar, algo así como una casa suntuosa a la que faltase la escalera, o un magnífico automóvil al que no le hubieran colocado el motor. [...] Hay mujeres guapas, otras simpáticas, otras inteligen-

47 Álvaro Retana, Las mujeres de Retana, Madrid, La Novela Corta, 1922, pp. 2-3. 
tes, y la gran mayoría de ellas no son más que unos pobres seres sin relieve incapaces de dialogar ${ }^{48}$.

Las mujeres de Retana, en cambio, presentan ricos matices de personalidad y no permanecen impasibles, ni a la espera de que un hombre las salve. De hecho, toman la iniciativa en muchos aspectos de la vida cotidiana, como las mujeres de su famoso cuplé "Batallón de modistillas":

Son los hombres con nosotras

en la paz muy bravucones

y nos tienen dominadas

sin dejarnos rechistar.

Pero en cuanto que nos vean

decididas a la lucha,

con las suegras en vanguardia,

de correr no pararán ${ }^{49}$.

$[\ldots]$

Dos tipos de mujer habitualmente denostados: la modistilla -pobre, analfabeta y que normalmente era burlada- y la suegra toman ahora el poder $y$ van a la misma guerra que sus compañeros, contribuyendo, de este modo, a romper con la habitual dicotomía modernista gobernada a turnos por la virgen María y a turnos por la femme fatale. En este sentido, el cuplé de Retana "Finca explotable" reivindica que los pies de la mujer, símbolo fálico representado obsesivamente durante el modernismo, sirven para bailar y hacer deporte, conectando así con una mujer más moderna:

La mujer es una finca, según pública opinión,

48 Joaquín Belda, Las mujeres de Belda, Madrid, La Novela Corta, 1921, p. 1. Para una comparativa entre los dos autores véase el trabajo de Alberto Sánchez Álvarez-Insúa, "La mujer en la literatura galante de período de entreguerras. Las mujeres de Joaquín Belda y Álvaro Retana", en La otra Edad de Plata. Temas, géneros y creadores (18981936), ed. Ángela Ena Bordonada, Madrid, Editorial Complutense, 2013, pp. 185197.

49 Álvaro Retana, “Batallón de modistillas: cuple’”. Véase Serge Salaün, El cuplé (19001936), Madrid, Espasa-Calpe, 1990, p. 246. 
y saber administrarla

es de muchos ambición.

Son los pies el piso bajo

y se deben reservar

para el baile y los deportes,

además de para andar.

Las rodillas, primer piso,

sólo tiene aplicación

para las que friegan suelos

o son de gran devoción.

$\mathrm{Al}$ amor se reserva

todo el piso principal,

procurando que no falte

la calefacción central.

Siempre fue el segundo piso

de segura explotación, pues la izquierda o la derecha

son de igual aceptación.

La azotea que es la cara

por la boca es un filón,

cuando se cultiva el beso

o algo de más sensación.

Y las manos, finalmente,

rendimiento pueden dar

en el cine, sobre todo,

si se saben manejar.

Mas conviene hacer presente

que en el piso del amor

nunca debe utilizarse

la escalera posterior ${ }^{50}$.

La riqueza de matices y dobles sentidos que ofrecen las letras de Retana ha sido estudiada extensamente por Javier Barreiro en varios trabajos, entre los que destaca su artículo "Álvaro Retana en la erotografía del primer tercio de siglo. Un acercamiento a los textos del cuplé sicalíptico”. Aquí, hace hincapié en las insinuaciones al acto sexual que presentan algunos de los cuplés del de Batangas y cita como ejemplo "La sortija estrecha":

50 Álvaro Retana, “Finca explotable”. Véase Javier Barreiro, op. cit., pp. 280-281. 


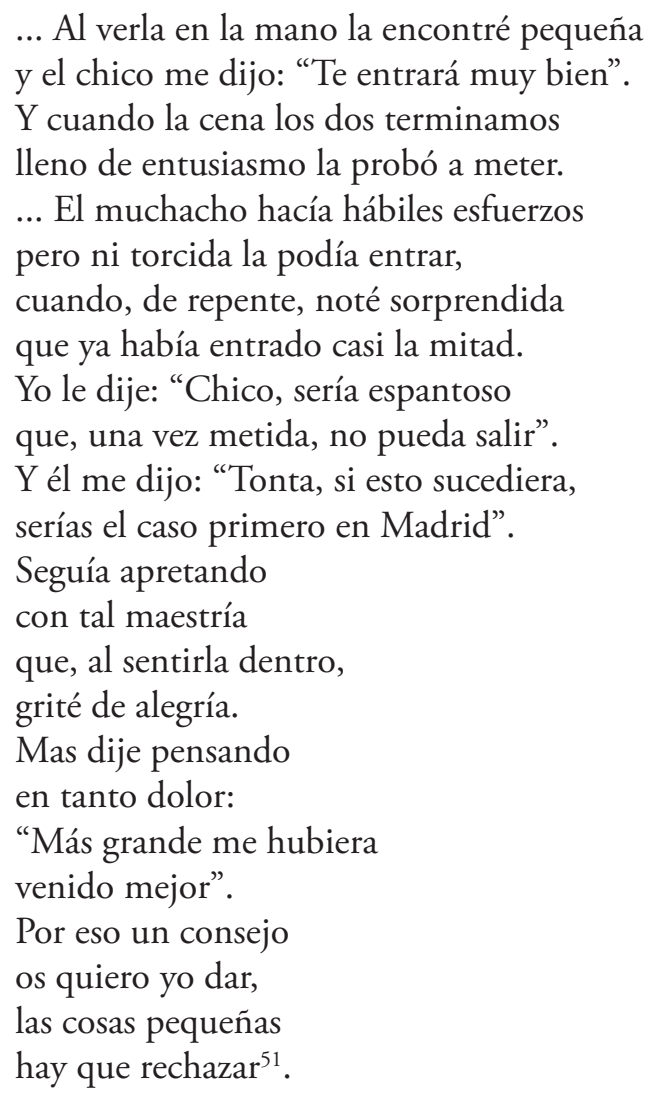

La estrechez de la sortija resulta en este punto oportuna para que la mujer reivindique su parte activa en la vida sexual. Suscribo totalmente la tesis de Maite Zubiaurre en Culturas del erotismo en España, según la cual, gracias al cuplé y a su representación explícita, múltiple y procaz del erotismo, las artistas de variedades asaltaron la escena con un importante mensaje que comunicar al público, e incluso a sí mismas: "que lo que estaba ocurriendo sobre las tablas podría acontecer con facilidad en el mundo 'real"”52. Así, las "damas honorables" que acudían a los teatros a escuchar a las cupletistas de belleza aristocrática -que es el adjetivo que más veces

51 Álvaro Retana, “La sortija estrecha”. Véase Javier Barreiro, op. cit., p. 282.

52 Maite Zubiaurre, op. cit., p. 298. 
les destina Retana en Historia del arte frivolo-, por mor de la magia de la moda podían ver en un mismo espectáculo a cocottes, gitanillas y castizas chulapas.

Su técnica para el diseño de figurines fue, como su biografía, un lienzo en el que crear y recrear diversos tipos de mujer. Tras el dibujo a lápiz de maniquís desnudos de rostro ambiguo [Fig. 10] comenzaba la fiesta: volantes para las rumbas, mantones para el cuplé, lentejuelas para la noche, escotes apetitosos [Fig. 11], pero también pantalones cortos para hacer deporte y trajes de chaqueta que abrieron, hace poco menos de cien años, un nuevo abanico de posibilidades de ser mujer y de entender y disfrutar de la sexualidad [Fig. 12].

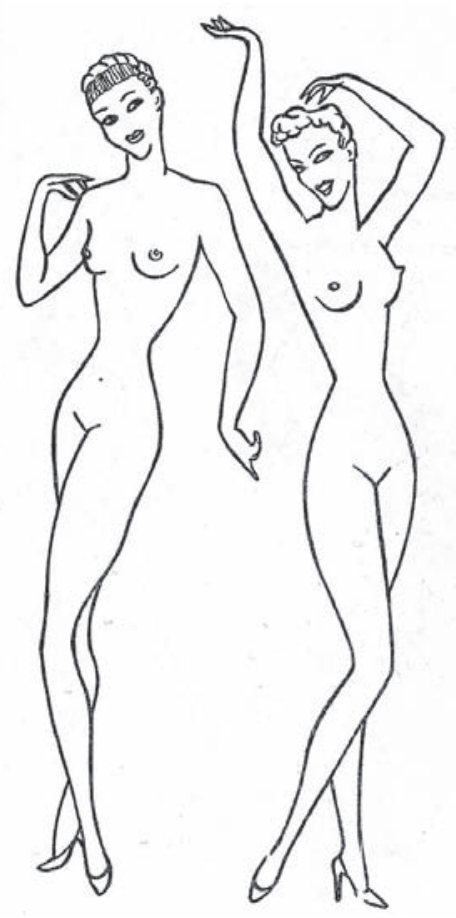

Fig. 10. Maniquís para vestir. Extraído de Álvaro Retana, El sumo pontifice de las variedades, Pilar Pérez

Sanz y Carmen Bru Ripoll, p. 75. 
Sara Toro Ballesteros, El escritor que se pintó a sí mismo: Los figurines de Álvaro Retana
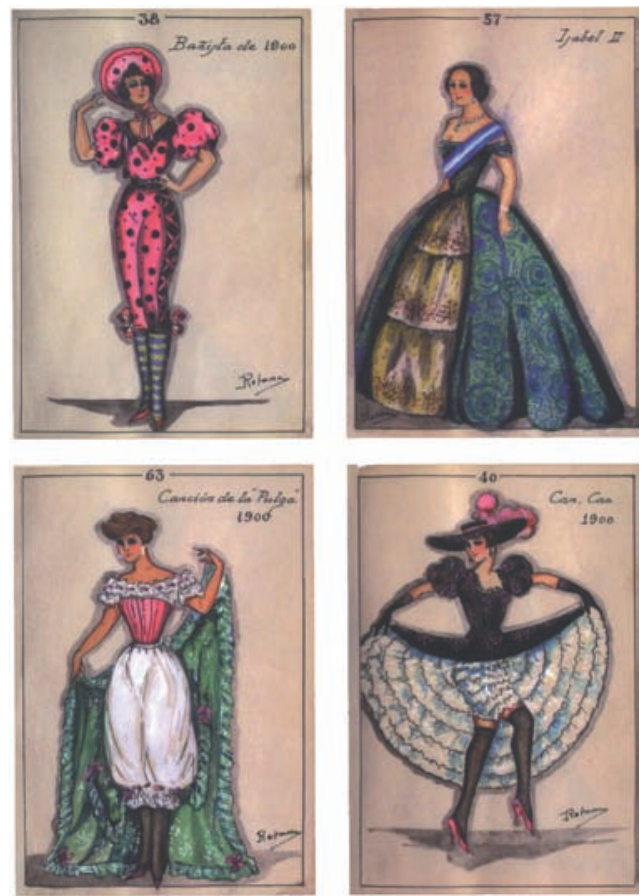

Fig. 11. Figurines de Álvaro Retana adquiridos por la BNE.

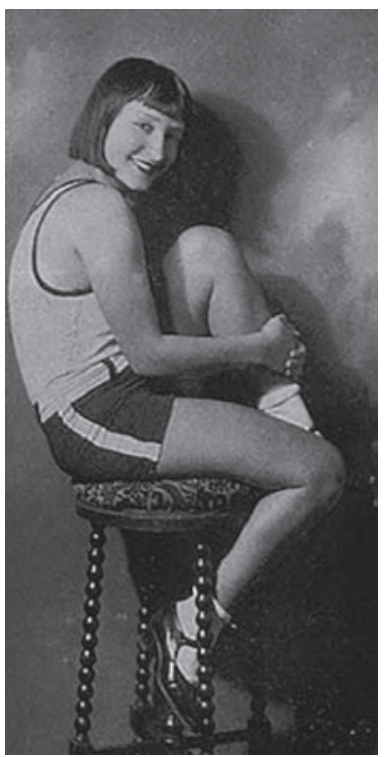

Fig. 12. Pepita Odena, extraído de Historia del arte frivolo de Retana. 